\title{
GLOBALIZACIÓN, MIGRACIONES Y EXPATRIACIÓN DE TRABAJADORES. LOS RETOS DEL DERECHO DEL TRABAJO Y DE LA SEGURIDAD SOCIAL FRENTE A LAS NUEVAS REALIDADES DE LA MOVILIDAD LABORAL INTERNACIONAL

\author{
Javier Fernández-Costales Muñiz
} \\ Reus, Madrid, 2018, 303 págs. \\ ISBN: 978-84-290-2102-8
}

\section{Susana Rodríguez Escanciano \\ Catedrática de Derecho del Trabajo y de la Seguridad Social Universidad de León}

No es empresa fácil presentar la monografía titulada "globalización, migraciones y expatriación de trabajadores: los retos del Derecho del Trabajo y de la Seguridad Social frente a las nuevas realidades de la movilidad internacional de trabajadores", pues disertar sobre su contenido y realizar una mención relativa a su autor desbordaría con creces el espacio asignado. Con un objetivo mucho más modesto, me limitaré a señalar que la riqueza del presente ensayo radica en un mérito fundamental: la excepcional personalidad del Dr. Fernández-Costales, siempre preocupado por el análisis de los temas clásicos adoptando una perspectiva actual sin abandonar la máxima solvencia científica. Sin duda, se trata de un profesor universitario bien conocido, no sólo por los colegas iuslaboralistas, sino también entre los juristas en general. Su impecable trayectoria profesional, avalada por la honestidad de sus publicaciones y el constante ofrecimiento de brillantes frutos de un trabajo realizado sin pausa, hacen innecesario que me extienda en destacar aspectos curriculares del autor como investigador.

Además de la calidad de la pluma, en esta ocasión, los comentarios que sobre la obra en presencia pudiera corresponderme hacer no resultan sencillos de formular, dada la exhaustividad y rigor del tratamiento proporcionado, acompañados de una finura jurídica incuestionable y de una perfecta combinación entre lo más erudito y doctrinal con la visión más pragmática que proporciona el gran conocimiento del tema analizado.

Bajo una certera premisa de observación y un atinado desarrollo sucesivo, los trazos fundamentales que constituyen el hilo conductor de la disertación se encuentran anclados en la multiplicación de los fenómenos de movilidad geográfica internacional de trabajadores y sus difusas aristas. Este es el elemento de reflexión y piedra angular 
de un atinado planteamiento convenientemente estructurado en distintos apartados perfectamente ubicados y engranados.

En la primera parte del trabajo, con la solidez y acierto que acostumbra, el Dr. Fernández-Costales realiza un excursus sobre el devenir del fenómeno migratorio, que ha sido una constante a lo largo de muchos siglos, convirtiendo a unos países en Estados receptores y a otros en emisores de una mano de obra generalmente movilizada desde entornos menos desarrollados hacia aquéllos en los cuales las posibilidades de alcanzar un mejor nivel de vida son, en principio, más elevadas. Esta visión histórica, ilustrativa a todas luces, no impide que el análisis se centre con visión preclara en las connotaciones actuales de las migraciones, marcadas por la globalización financiera y la deslocalización de las grandes empresas.

En la segunda parte, el autor abandona los planteamientos tradicionales en aras a desbrozar cómo afectan al Derecho del Trabajo las nuevas realidades de la movilidad internacional. A tal fin, aborda la tímida evolución de la preocupación mantenida por la Unión Europea hacia las cuestiones sociales, descendiendo a los vidriosos conceptos de desplazamiento y de trabajador extranjero, sin dejar de alertar sobre la naturaleza jurídica de la verdadera movilidad geográfica, es decir, aquella que no supone la incorporación del trabajador in itinere al mercado de trabajo del país de destino. Varios han sido los principios básicos de la construcción europea sobre esta realidad: equivalencia, libertad de establecimiento y prestación de servicios, libertad de circulación de los trabajadores y competencia leal. Tales postulados, manejados con presteza en el presente estudio, hacen que lo importante no sea la nacionalidad del trabajador sino el lugar de establecimiento de la empresa con la cual está vinculado. Singular importancia va a tener en este contexto el Convenio de Roma, de 19 de junio de 1980, sobre ley aplicable a las obligaciones contractuales, sustituido por el Reglamento (CE) núm. 593/2008, de 17 de junio, así como la Directiva 96/71, de 16 de diciembre, sobre el desplazamiento de trabajadores efectuados en el marco de una prestación de servicios, modificada por la Directiva 2018/957, de 28 de junio. Tales fuentes normativas han sido tratadas con detalle, consiguiendo con éxito superar la dificultad de agrupar o encerrar las distintas variantes imbricadas en sus contornos precisos.

El verbo empleado no pierde su seriedad cuando profundiza, dentro de la cuarta parte, en los aspectos procesales del desplazamiento internacional de los trabajadores, pues no pocos son los litigios y controversias a dirimir ante los Tribunales. El autor es consciente de que en este ámbito los regímenes para determinar la ley aplicable y el tribunal internacionalmente competente persiguen, en lo esencial, objetivos comunes, como son uniformar las reglas, asegurar la autonomía de las partes sin perjuicio de la tutela y protección de la parte más débil, promover la coincidencia entre el derecho aplicable y el tribunal competente, permitir la libre circulación de las decisiones judiciales, reforzar la protección de las personas domiciliadas en la Unión mediante la previsibilidad del órgano judicial a quo, asegurar la proximidad del tribunal al litigio y promover la buena administración de justicia y la correcta organización del proceso. Singularmente evocadores son los apartados dedicados a los foros de competencia en el Reglamento 1215/2012, de 12 de diciembre, y a la prueba del derecho extranjero. Asimismo, y con una extraordinaria lucidez expositiva en un tema 
harto complejo, desgrana los litigios y controversias que los Tribunales españoles tienen que resolver aplicando las disposiciones propias de un ordenamiento extranjero, estableciendo, al tiempo, los efectos y consecuencias de la alegación y prueba de dicho sistema jurídico, así como de la falta de acreditación, dando cuenta, a la postre, de la polémica judicial existente, sin dejar de aportar atinadas soluciones.

La parte quinta se dedica a la proyección de los movimientos migratorios sobre la Seguridad Social, no en vano el hecho de que el trabajador migrante acceda al mercado de trabajo en el país de destino pone de manifiesto las diferencias existentes entre los sistemas nacionales de protección social a los que el empleado se podría vincular. De ahí la conveniencia de descender al detalle del impulso de armonización y coordinación dirigido al amparo de los derechos adquiridos en cada uno de los Estados en los que se haya desarrollado la actividad a lo largo de la vida laboral, desglosando los principios de igualdad de trato, de exportación de pensiones y conservación de los derechos en curso de adquisición (totalización, prorrateo y no acumulación).

La sexta parte se adentra con atinada decisión en los aspectos colectivos del desplazamiento, atendiendo a las peculiaridades de sindicación, reunión, huelga y representación de los trabajadores desplazados a España, sin dejar de alertar sobre los problemas que plantea la negociación colectiva en el marco europeo.

La séptima parte aborda el tema de la prevención de riesgos laborales de los trabajadores en desplazamientos internacionales, tanto en lo que afecta a las obligaciones impuestas como en lo que se refiere a las responsabilidades a asumir por los sujetos concernidos, aproximándose de forma original y novedosa a problemas y cuestiones hasta ahora apenas tratadas por la doctrina.

En fin, si correcto ha sido el discurso seguido no lo es menos el colofón de la obra, es decir, el último capítulo en el que se tratan las cuestiones más actuales, centradas principalmente en las dificultades del acceso al empleo, así como las perspectivas de futuro en materia de inmigración, emigración y trabajadores extranjeros en España.

Como el lector comprobará, esta breve semblanza no puede acoger, y ni tan siquiera esbozar a riesgo de desmerecer o distorsionar, la riqueza del contenido de una obra tan densa. Antes al contrario, el propósito se ha ceñido a poner de manifiesto que se trata de una oportunidad excepcional para acercarse a un tema transversal y abierto analizado con solvencia desde una impecable sistemática. La monografía en presencia se perfila, pues, como un instrumento, no ya útil o recomendable, sino del todo imprescindible para cualquier persona interesada en la materia jurídico-laboral. 